
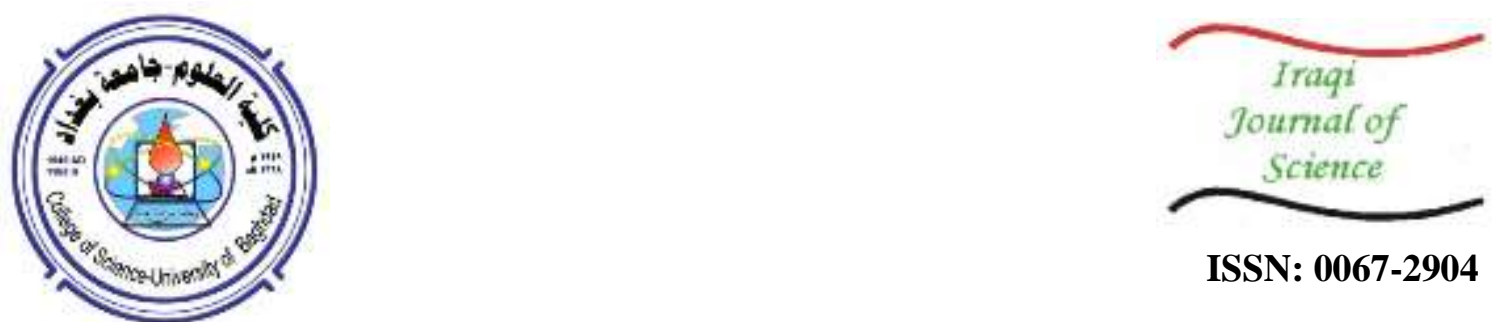

ISSN: 0067-2904

\title{
Utilizing Cold Plasma in Preparing Silver Nanoparticle from Origanum Vulgare
}

\author{
Sabah N. Mazhir**1, Iman A Mohammed ali ${ }^{1}$, Hazim I. Al-Ahmed ${ }^{2}$ \\ ${ }^{1}$ Department of physics, College of Science for women, University of Baghdad, Iraq. \\ ${ }^{2}$ Biotechnology Research Center/ Al-Nahrain University/ Iraq
}

\begin{abstract}
Received: 24/3/ 2019
Accepted: 18/6/2019

Abstract

In this research, we obtained nanoparticles (NPs) using a type of microwave (cold plasma) and water extract from Origanum vulgare with the addition of silver nitrate (AgNO3) solution. Silver nanoparticles are characterized by high production techniques. Experimental factors such as morphology, structure, optical properties and active compounds of the nanoparticle extract were studied through specific tests such as morphology, UV spectroscopy, FE-SEM, FT-IR, and Atomic Force Microscopy (AFM). Plants were used in manufacturing the nanoparticles, as plants are well known for their accessibility and applicability in different pathological areas. The current research provides information on the Green Union System of Nanoparticles. It is concluded that, under the influence of cold plasma, the nanoparticles increased the nanoscale size of the molecules and thus increased the aggregation and the transformation of the pink color of the nanocrystal line to brown due to increased absorption.
\end{abstract}

Keywords: Cold Plasma. O. vulgare, Nanoparticle.

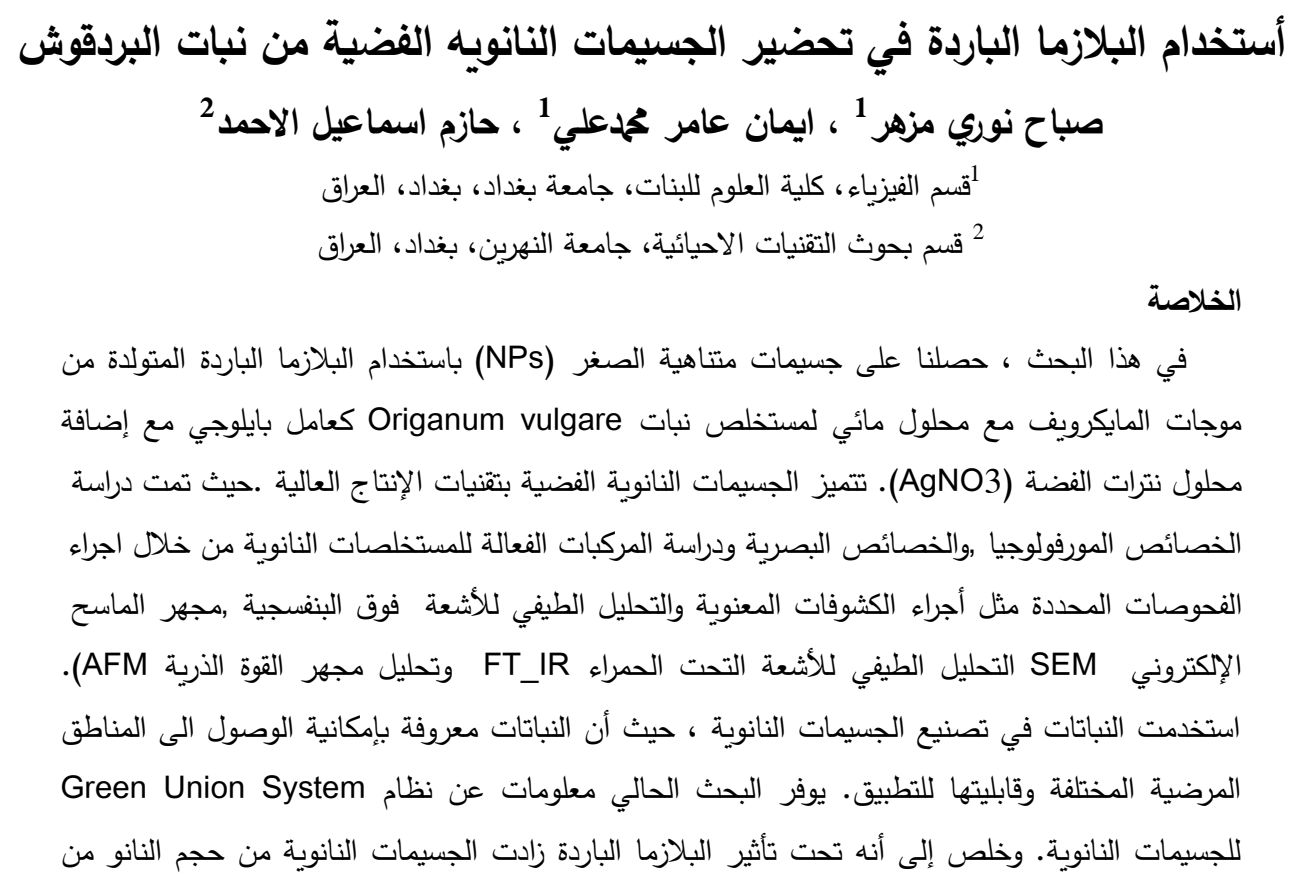

*Email: drsabah6688@gmail.com 


$$
\text { الجزيئات وبالتالي زيادة التجميع وتحويل اللون الوردي من خط الكريستال النانوي إلى اللون البني بسبب زيادة }
$$

$$
\text { الامتصاص }
$$

\section{INTRODUCTION}

Nanomaterials are defined as materials of external dimensions and / or internal structures within the nanometer scale $(\mathrm{nm})$. The $100 \mathrm{~nm}$ scale is adopted by many organizations/countries to distinguish between large nanoparticles and macromolecules [1]. This field is known as nanotechnology, which allows us to produce nano-scale apparatus. Nanoparticles can effortlessly move through blood vessel walls, or even insert themselves into most of body cells and cell membranes in organisms, which enable them to be interacted quickly with biological systems [2]. The exact size of the nano system in all these organizations/states is about $100 \mathrm{~nm}$. These materials are of different dimensions and shapes, including 0D, 1D, 2D or 3D, depending on the general shape. Researchers found that the size could affect the physical and the chemical properties of the material as it becomes more effective as the size of the particles is smaller than their normal seize, For example, the NPs of gold ( $\mathrm{Au})$, platinum $(\mathrm{Pt})$, silver (Ag) and palladium (Pd) have remarkable optical proeperties (color) of red wine shading, yellow, dark, and dim dark black, respectively, which can be utilized in biomedical applications $[3,4]$. The shade of the solution changes because of the variety in the dimensions, the thickness of the nanostructure and the focus of silver in the arrangement. Changing any of the above components influences the ingestion properties of NPs and, in this way, the gradient is monitored in different absorption colors $[1,5,6]$. Green methods for AgNP synthesis were described to eliminate the toxicity of the metals and the reduction methods used. The chemical method identifies three major factors for the synthesis of green synthesis, including the use of a non-toxic fixing agent, the choice of solvent intermediary and the use of a natural reduction factor, while the green methods are classified as a biological method [7.[

This work focuses on the exploitation of O. vulgare, which is not used in the green synthesis of nanoparticles. O. vulgare, a traditional herb used throughout the world for moderate respiratory disorders, is used to relieve indigestion, dental diseases, rheumatoid arthritis, urinary tract disorders and infections. Previous studies showed that this plant has effective anti-diabetic, anti-oxidant, and antibacterial properties of the metal. The aim of this research is to describe the green union of silver nanoparticles using aqueous solution of $O$. vulgare [8]. Plasma is an ionized gas composed of approximately equal numbers of positively charged ions and negatively charged electrons [8]. Nonthermal plasma is used here. Microwave plasma contains high frequency electromagnetic radiation in the $\mathrm{GHz}$ band along with microwave power of $800 \mathrm{~W}$, and it uses argon gas to generate the torch. The plasma system produced by the microwave is preferred over other types of plasma sources, hence, the task of replacing or cleaning the electrodes and threads is avoided [9, 10]. Microwave discharges produce unbalanced plasma because electrons can respond to electric field oscillations while ions cannot respond because of their large mass. Thus, most of the microwave energy goes preferentially to the electrons, leading to the production of plasma that is far from the thermodynamic equilibrium [11, 12].

\section{MATERIALS AND METHOD}

The microwave plasma generated from this system were applied on rabbits (Figure-1) with 2.45 $\mathrm{GHz}$ microwaves frequency using Argon gas, $175 \mathrm{~V}$ applied voltage, $2 \mathrm{~L} / \mathrm{min}$ argon gas flow rate and $10 \mathrm{~m}$ discharge tube diameter. 


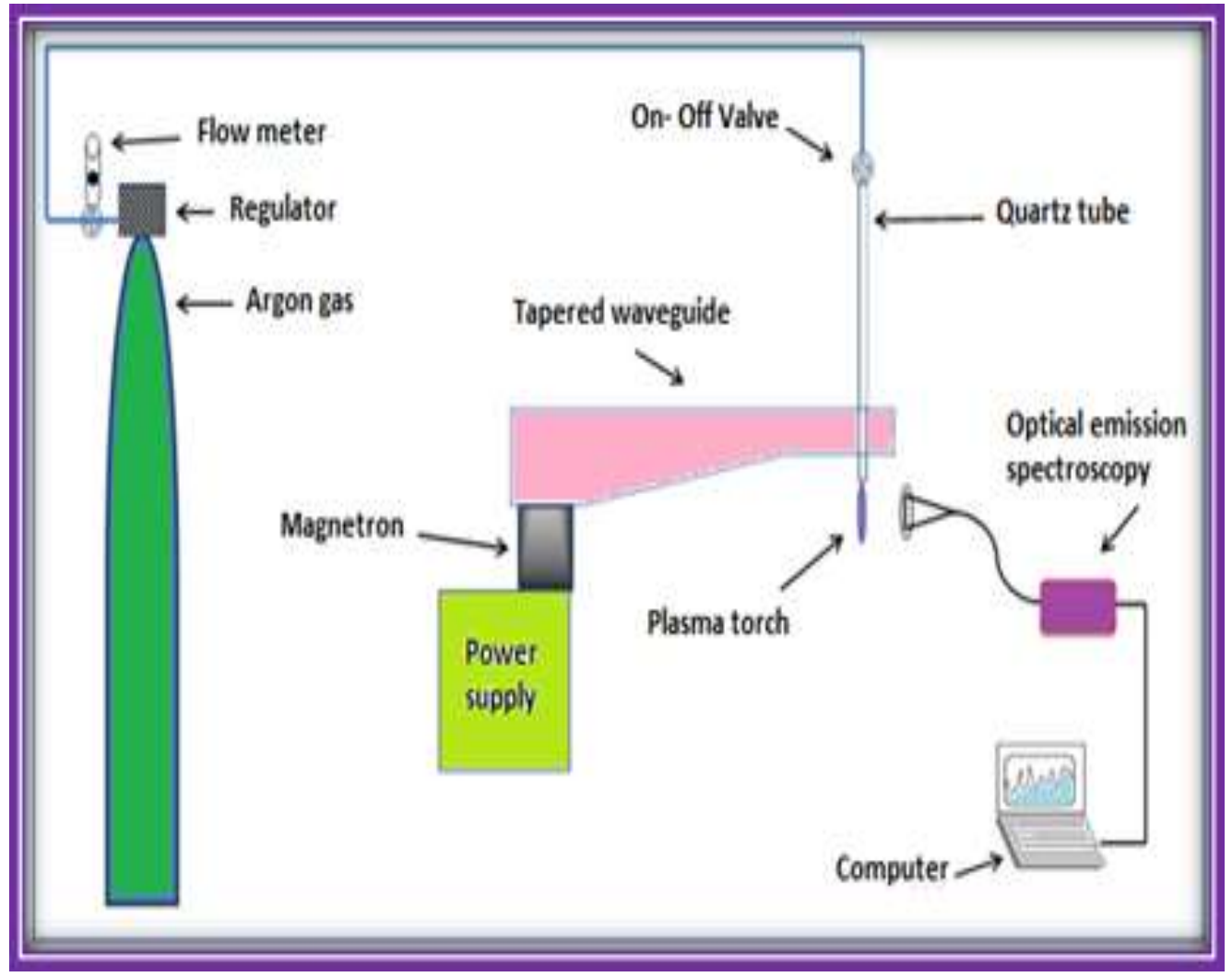

Figure 1-a schematic diagram of the MIPJ system

\section{Preparation of a water extract of marjoram}

$O$. vulgare was used after being washed several times with deionized water to remove dust particles and then sun dried to remove the residual moisture. Marjoram leaves were grinded using a regular mill and then $10 \mathrm{~g}$ of marjoram powder mixed with $100 \mathrm{ml}$ of deionized water (DIW). The water solution was boiled on hot magnetic stirrer $\left(60-90{ }^{\circ} \mathrm{C}, 10\right.$ minutes). The water solution was cooled and then placed in a centrifuge for 15 minutes at $6000 \mathrm{rpm}$. The water solution was filtered using filter paper with a diameter of $2 \mathrm{~cm}$. To know the concentration of the active substance in the water solution, the weight of the dish without the casing and without the water solution was found to be $7.13 \mathrm{gm}$, to which $5 \mathrm{ml}$ of the water solution was added and left to dry. The dish weighted again, and it was found $7.53 \mathrm{gm}$ with water solution and put Result: The concentration of the active substance in the solution was $0.4 \mathrm{gm} / 5 \mathrm{ml}$.

\section{Preparation of the Nano extract from the $O$. vulgare solution.}

The molar was converted to gram weight using the following steps:

1. $1 \mu$ is equivalent to $169.8 \mathrm{gm}$

2- 1 is $\mathrm{m} \mu$ equivalent to $0.170 \mathrm{gm}$

$0.085 \mathrm{~g}$ of silver nitrate powder was taken and diluted in $50 \mathrm{ml}$ of DIW. Using the burette, $50 \mathrm{~mL}$ of silver nitrate solution was added to $5 \mathrm{~mL}$ of marjoram solution with the use of a hot plate with a magnetic drive at $60-90{ }^{\circ} \mathrm{C}$. The $O$. vulgare solution was converted to a Nano extract. The conversion of the solution into nanotubes could be observed from the change of the light color to reddish browns. This is the first evidence of the composition of nanoparticles. This process was performed after we diluted the plant extract several times and using the centrifuge

\section{Preparation of the Nano extract from the $O$. vulgare solution by using cold plasma}

Silver nitrate powder $(0.085 \mathrm{~g})$ was diluted in $50 \mathrm{ml}$ of DIW. Using burette, $50 \mathrm{ml}$ of silver nitrate solution was added to $5 \mathrm{ml}$ of the $O$. vulgare solution with the use of a hot plate with a magnetic stirrer at $60-90^{\circ} \mathrm{C}$. The final extract was subjected to cold plasma for 10 minutes. Argon gas was used at pressure of 5 bars, with continuous mixing of the extract. 


\section{RESULTS AND DISCUSSION}

In this research, the preparation of the green nanoparticle of the O.vulgare plant was discussed using physiologic and biological methods. Nanoparticles of less than $100 \mathrm{~nm}$ were obtained after confirming the properties of the particles using different tests.

Quality tests to identify active ingredients in water extracts from $O$. vulgare and Nanoparticle.

Chemical analysis was used to determine the effective compounds of the extract. Plants containing active compounds in the metabolic products are called industrial plants, in addition to the medicinal properties they possess. The plant is used directly in the treatment of many diseases. It is also used to improve the properties of many compounds and reduce their toxicity, which is included in research experiments used in medicine. Various studies showed that $O$. vulgare has many medicinal and therapeutic properties. Therefore, the active compounds of $O$. vulgare were studied, and the results showed that the active compounds contained in the herb after being converted into a water extract include flavonoids, phenols, resins, essential oils, saponins, terpenoides and tannins [13]. While, the nanoparticle $\mathrm{O}$. vulgare for the same water extract of $O$. vulgare had the same effective compounds, with no resins and a low percentage of volatile oil. From this examination, it is possible to consider that the effective compound resin is the main compound in the silver nanoscale, in addition to other compounds; Resins are the basic elements that combine with the nitrate salts used in the preparation of the nanoparticle. The results are demonstrated in Table-1.

Table 1-show the active compounds present in both the water extract of $O$. vulgare plant and the Nano extract of the same plan

\begin{tabular}{|c|c|c|c|}
\hline Sequence & Effective compound & $\begin{array}{r}\text { Result of directory } \\
\text { detection } O \text {. vulgare }\end{array}$ & $\begin{array}{c}\text { Result of directory } \\
\text { detection(Nano) }\end{array}$ \\
\hline 1 & Alkaloids & - & - \\
\hline 2 & Flavonoids & + & + \\
\hline 3 & Phenolic & + & + \\
\hline 4 & Resins & + & + \\
\hline 5 & Essential Oil & ++ & + \\
\hline 6 & Saponin & + & + \\
\hline 7 & Terpenoides & - & + \\
\hline 8 & Tannins & + & + \\
\hline
\end{tabular}

(+) the nanoparticle contains the active substance

(-) The non-containment of the nanoparticle is the active ingredient type

Characterization of Silver nanoparticles

UV-Vis spectral analysis

Nanoparticles are known in metals that interact strongly with the lights at certain wavelengths. Therefore, UV-visible is an effective tool in the identification and characterization of the kinetic composition and absorption of nanomaterials. The process of formation of nanoparticles was observed by ultraviolet spectroscopy. Figure-2 shows the ultraviolet-physical spectra of the formation of AgNPs and other nanoparticles. In this study, we found that the color changed in nanoparticles with leaves of water extract from $O$. vulgare. The transition to reddish was observed at $60-90^{\circ} \mathrm{C}$ and $20-25 \mathrm{~min}$. This explains the transformation of $\mathrm{Ag}+$ ions. 


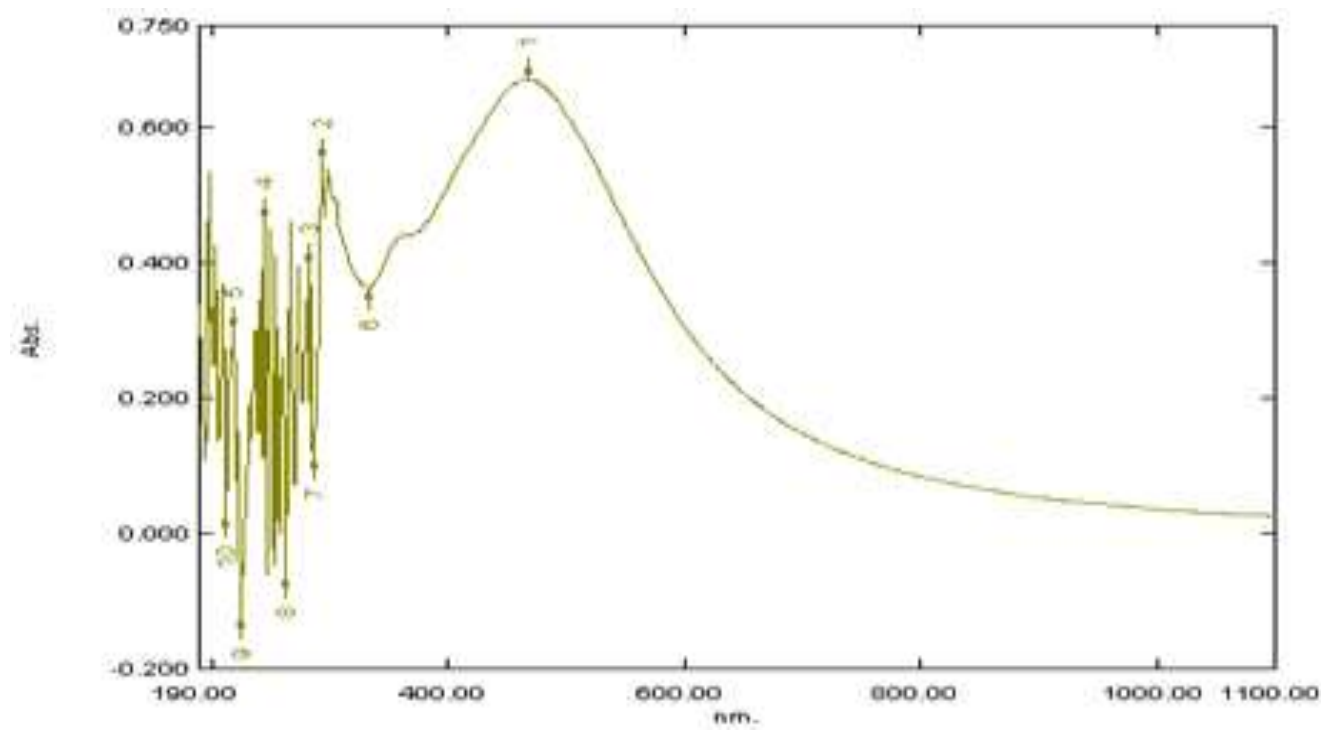

Figure 2-UV-Visible spectral analysis of NPs

The peaks of the surface Plasmon's are centered at $480 \mathrm{~nm}$, with broadband spectrum, and the size and shape of the nanoparticles can be identified by high peak absorption, low bandwidth and an increase in the measurement range. There is an inversely proportion between size of particles and absorption; the smaller the particle size the higher the absorption. The number of particles leads to an increase in absorption. The graph shows small spherical particles and other shapes. It can be noted that the presence of proteins in the water extract from the $O$. vulgare leaves lead to the degradation of precursor metals and the formation of extracellular metal oxides confirmed by FTIR spectroscopy. The spectra of NPs obtained were consistent with the previously reported results [3, 4].

On the other hand, Figure-3 shows the ultraviolet-physical spectra of the formation of NPs. It was found that the color changed to brownish. Surface Plasmon's ranges were extended at $440 \mathrm{~nm}$. The graph shows small spherical particles with some agglomeration.

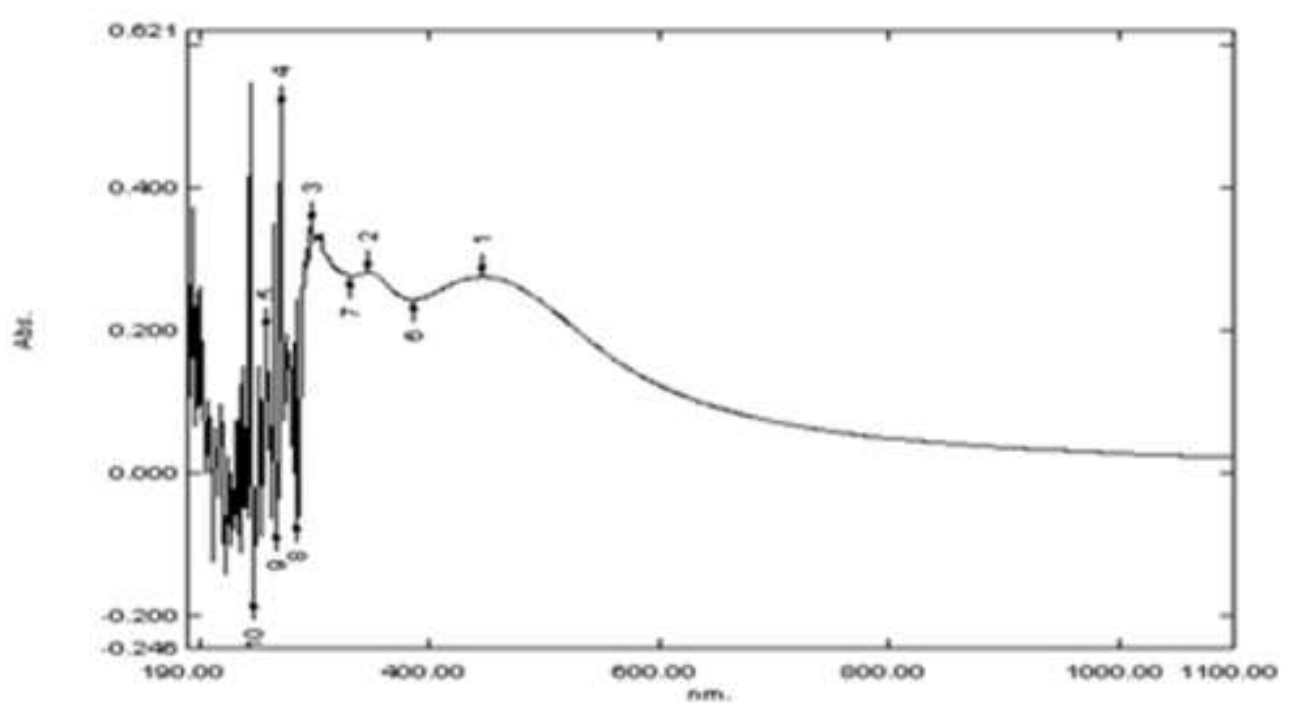

Figure 3-UV-Visible spectral analysis of NPs+P

\section{FT-IR analysis of nanoparticles}

FT-IR spectroscopy is an important tool in determining functional groups. The type of vibratory transitions produced by the movement of electrons determines the relationship between metals and plant molecules and their role in the synthesis of nanoparticles. In this work, FT-IR analysis was performed to identify the active molecules responsible for inhibition and stabilization of nanoparticles. Figure-4 which is related to $O$. vulgare sheets shows a number of peaks reflecting the complex nature 
of the $(\mathrm{O}-\mathrm{H})$ extract. It is characterized by high absorbency and sharp peak (at $3448.72 \mathrm{~cm}^{-1}$ ), with $\mathrm{CH}_{3}$ compounds extending at $2931.80 \mathrm{~cm}^{-1}$ and the alkene group at $1635.64 \mathrm{~cm}^{-1}$. In addition, peaks of condensation between $1489.05 \mathrm{~cm}^{-1}$ and $894.97 \mathrm{~cm}^{-1}$ indicate the presence of functional groups such as C-CL, C-O, C-N, C-C, and N-O. These groups explain the role of green synthesis in the formation of nanoparticles, while the water abstraction shows the appearance of vibrations at the wavenumber 2005.97 which includes the set $\mathrm{C}=\mathrm{O}$.

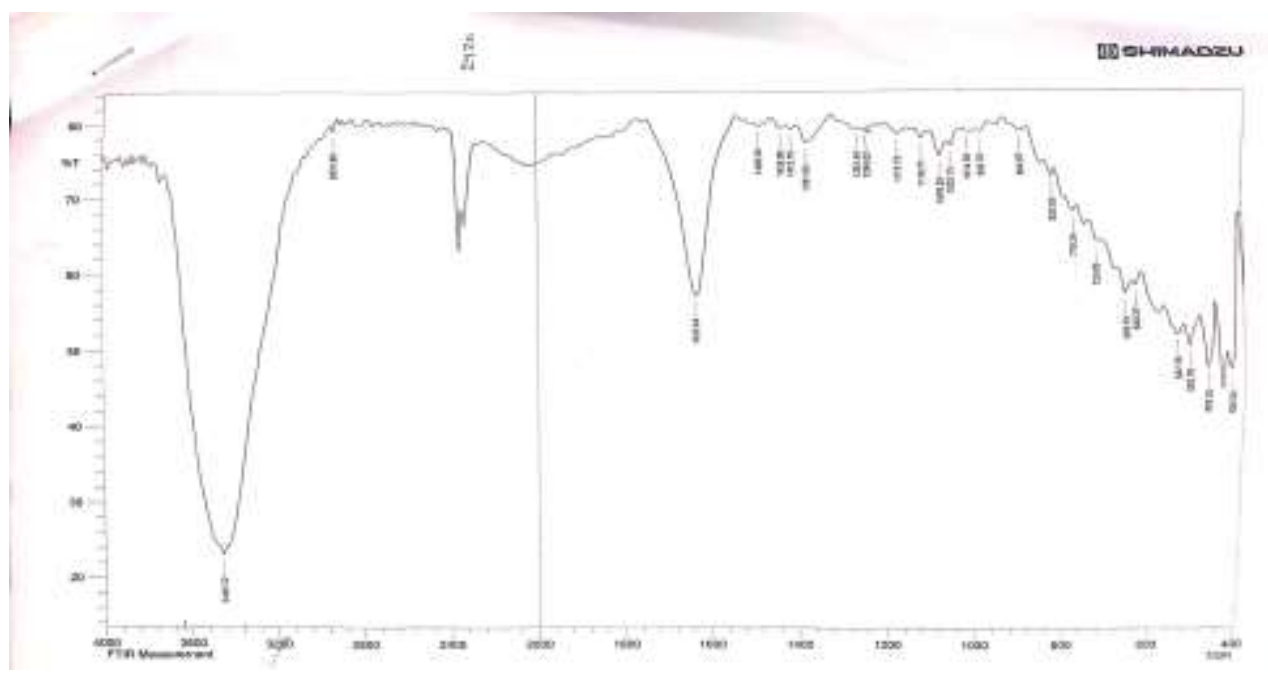

Figure 4-FT-IR analysis of NPs

\section{Field emission-scanning electron microscopic (FE-SEM) studies}

The electron microscopy (FE-SEM) was used to determine surface morphology of the nano-silver groups. The FE-SEM test was used to determine the synthesis of the nanoparticles, the size and shapes of molecules, the amount of mass and the degree of variation between molecules. The $O$. vulgare feed was used to form a spherical shape at assembly. The size of the nanoparticles was found to be 44.3$88.1 \mathrm{~nm}$, which falls within the size of the nanostructures. We accept the fact that the high concentration of the biologically active compounds in the colloidal solution might cause the conglomeration of the nanoparticles. The shape of the nanoparticles was reported to significantly alter its optical and electronic properties (Figure-5).

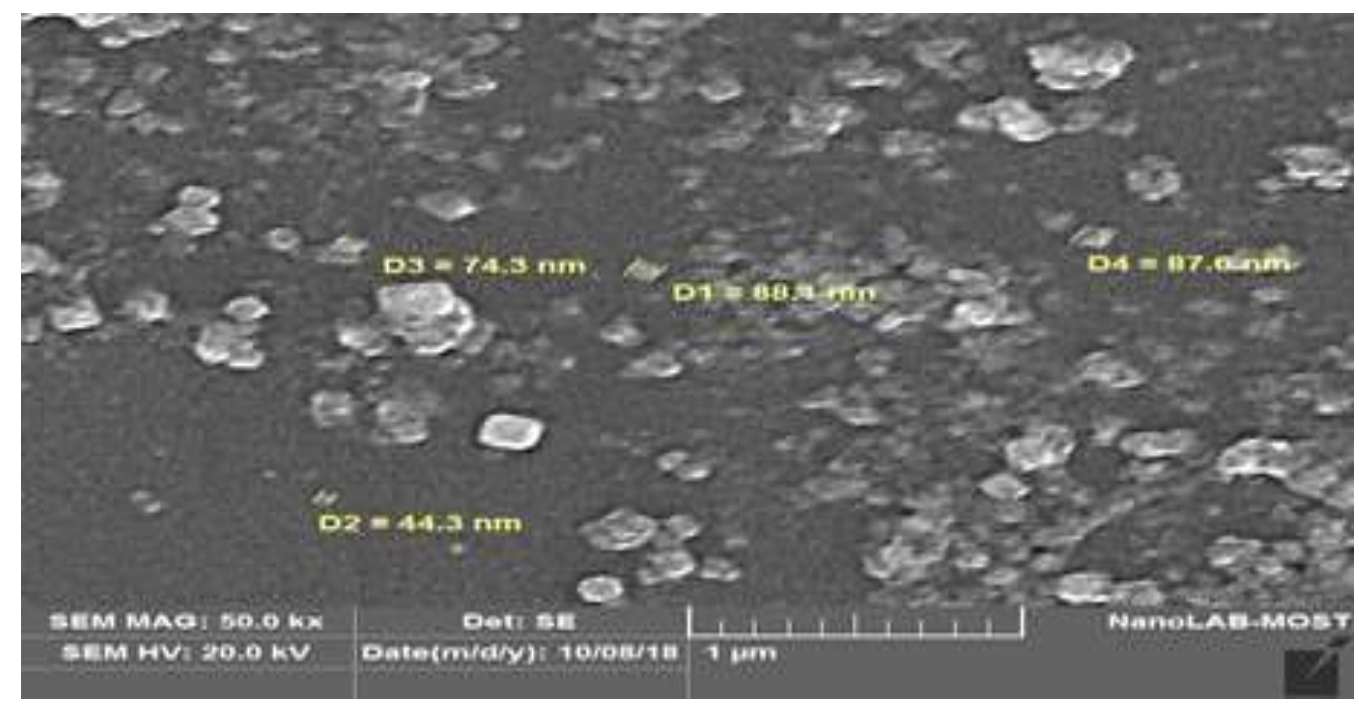

Figure 5-FE-SEM of silver nanoparticles 
On the other hand, the size of the nanoparticles was found to range from 44.2 to $86.1 \mathrm{~nm}$, which lacked dispersion due to the use of cold plasma energy. We accept the fact that the high concentration of the biologically active compounds in the colloidal solution and the effect of plasma energy might cause the observed mass of the nanoparticles. Therefore, the ultrasonic device was used to disperse the sample before use. It was reported that the nanoparticle shape significantly altered its optical and electronic properties (Figure-6).

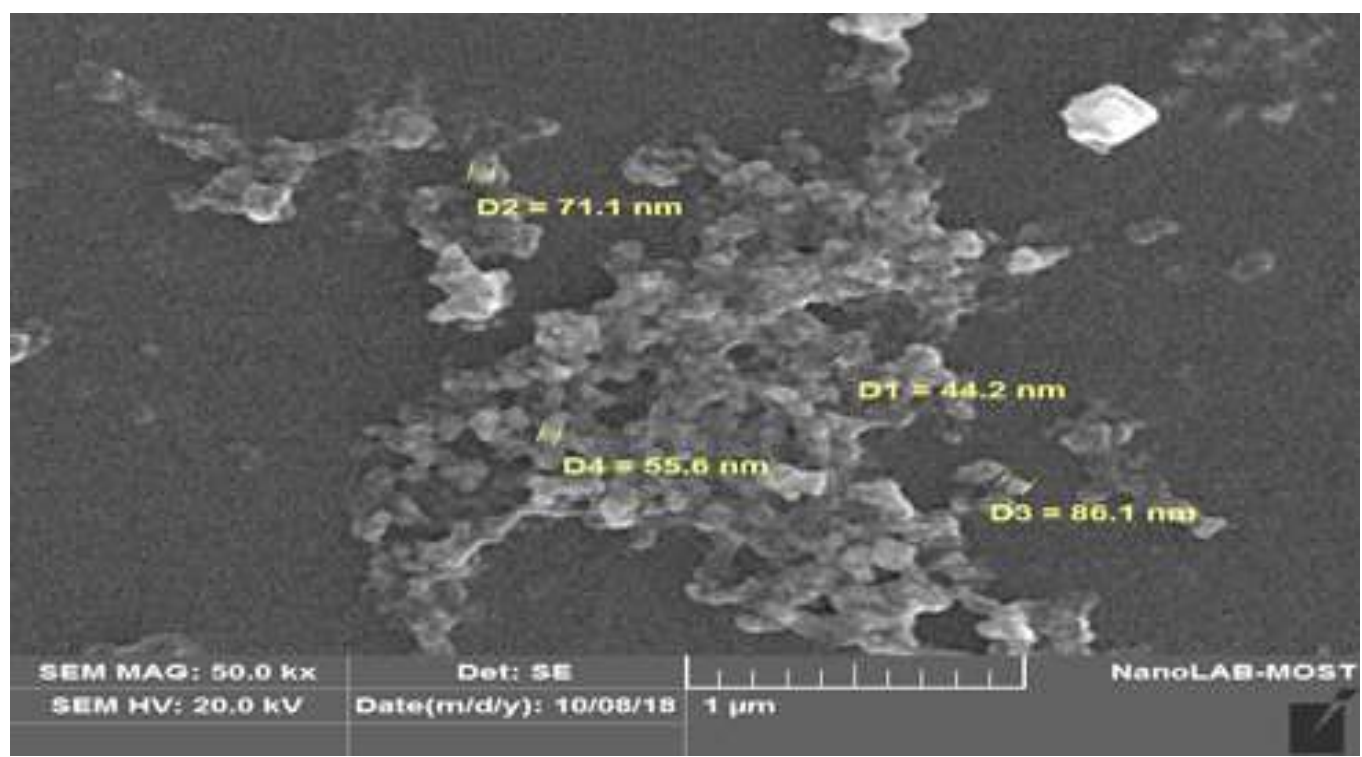

Figure 6-FE-SEM of Sliver nanoparticles under the influence of cold plasma

\section{Atomic force measurement (AFM)}

AFM is used to give some information about the surface morphology of the material (2D and 3D). Figure-7 shows microscopic images of the atomic force of the prepared sample. The dark gradient represents the size of the particles smaller than those with the flowered color, which represents the size of the largest nanoparticles. Nanoparticles prepared using $O$. vulgare appear to combine biological and chemical preparations.

A
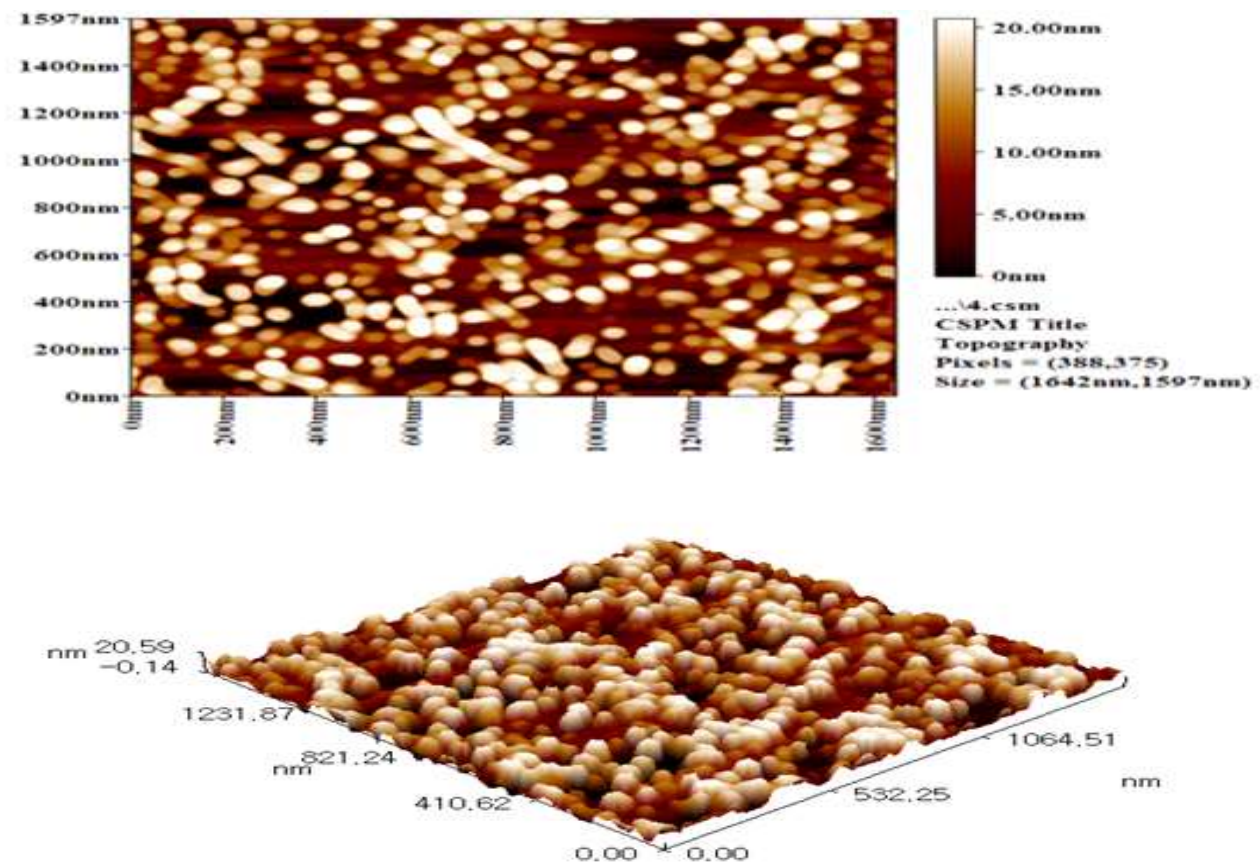

Figure7-A: 3D \& B: 2D AFM images of NPs 
Figures-8 shows microscopic images of the sample prepared using O. vulgare and cold plasma. It was observed that the shape of the particles was mostly spherical and cylindrical.

A
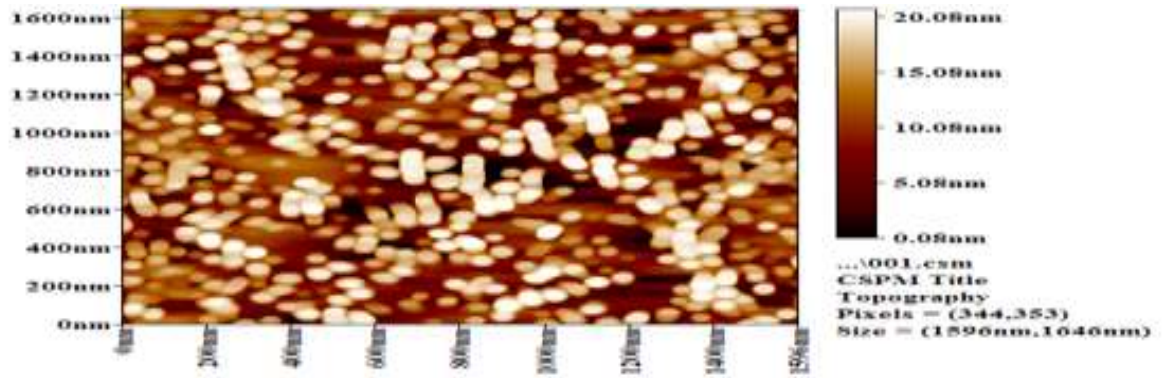

B

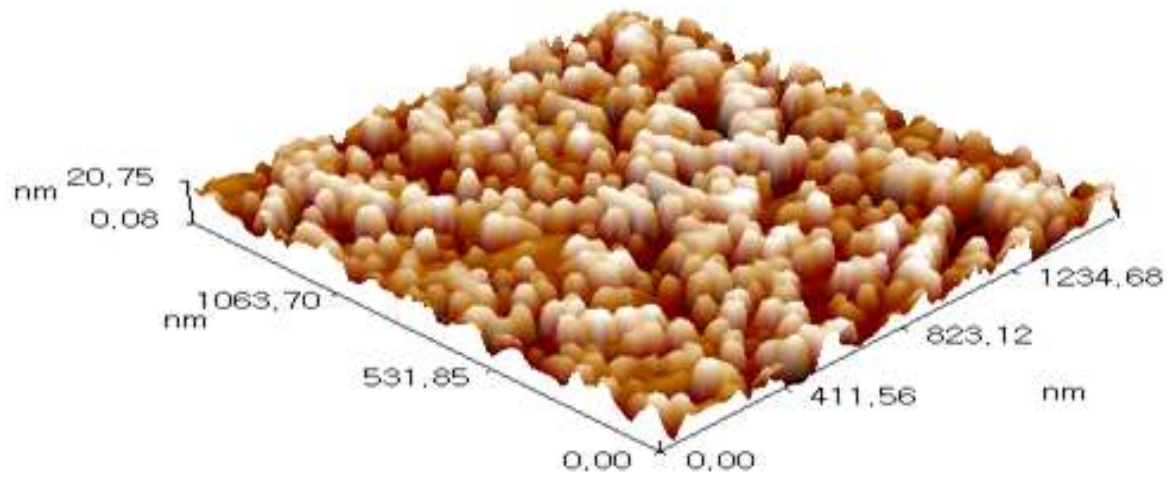

Figure 8 A-3D \& B: 2D AFM images of NPs+P

AFM imaging of nanoparticles was performed by drying the substrates on a clean glass slide. Surface morphology was studied using AFM images that provide very high magnification images. It is a useful tool to clearly illustrate the size, distribution and shape of nanoparticles. The AFM measurement results are shown in Figure-9 which demonstrates the granular distribution of the NPs prepared in green chemistry. The graph shows that $10 \%$ of the particles are $35.00 \mathrm{~nm}, 50 \%$ are 50.00 $\mathrm{nm}$, and $90 \%$ are $60 \mathrm{~nm}$ in size, while the average size particle was about $50.02 \mathrm{~nm}$.

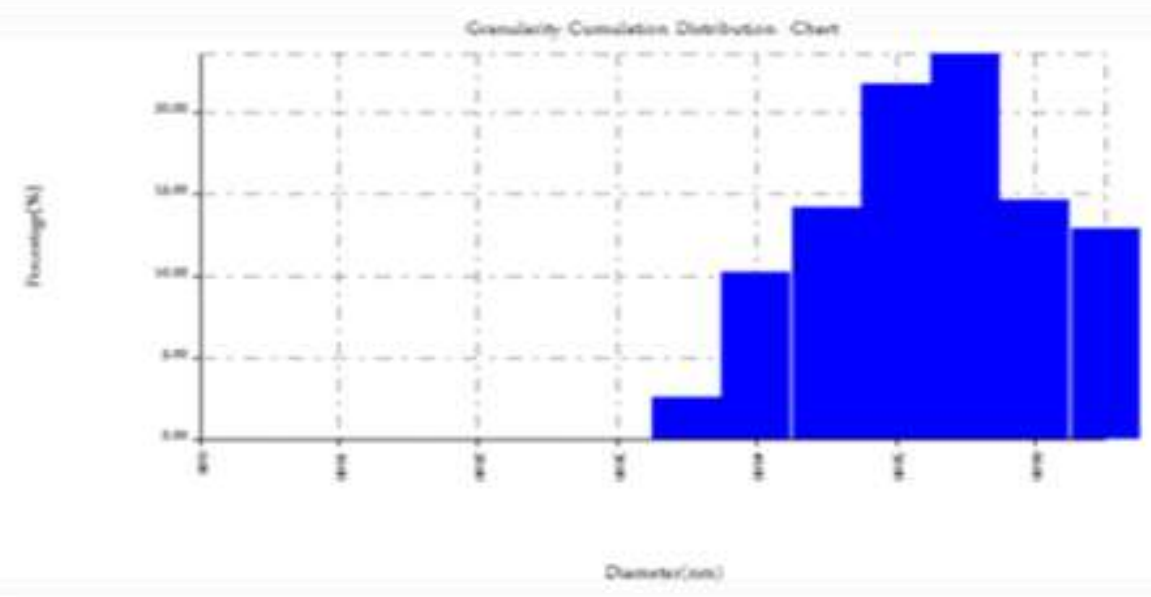

Figure 9-Granularity distribution of Ag NPs by chemical method

Figure-10 refers to the granular distribution of Ag NPs synthesized by $O$. vulgare water extract using $\mathrm{Ag} \mathrm{NO}_{3}$ and cold plasma. The graph shows that $10 \%$ of the particles are $50.00 \mathrm{~nm}, 50 \%$ are $60.00 \mathrm{~nm}$ 
and $90 \%$ are $80.00 \mathrm{~nm}$ in size, while the average particle size is about $65.95 \mathrm{~nm}$. From this examination, we conclude that the biological preparation of the nano couple gives properties of the nanotubes better than the use of cold plasma, because plasma energy enables interaction between the active compounds, leading to a conglomeration, thus increasing the particle size.

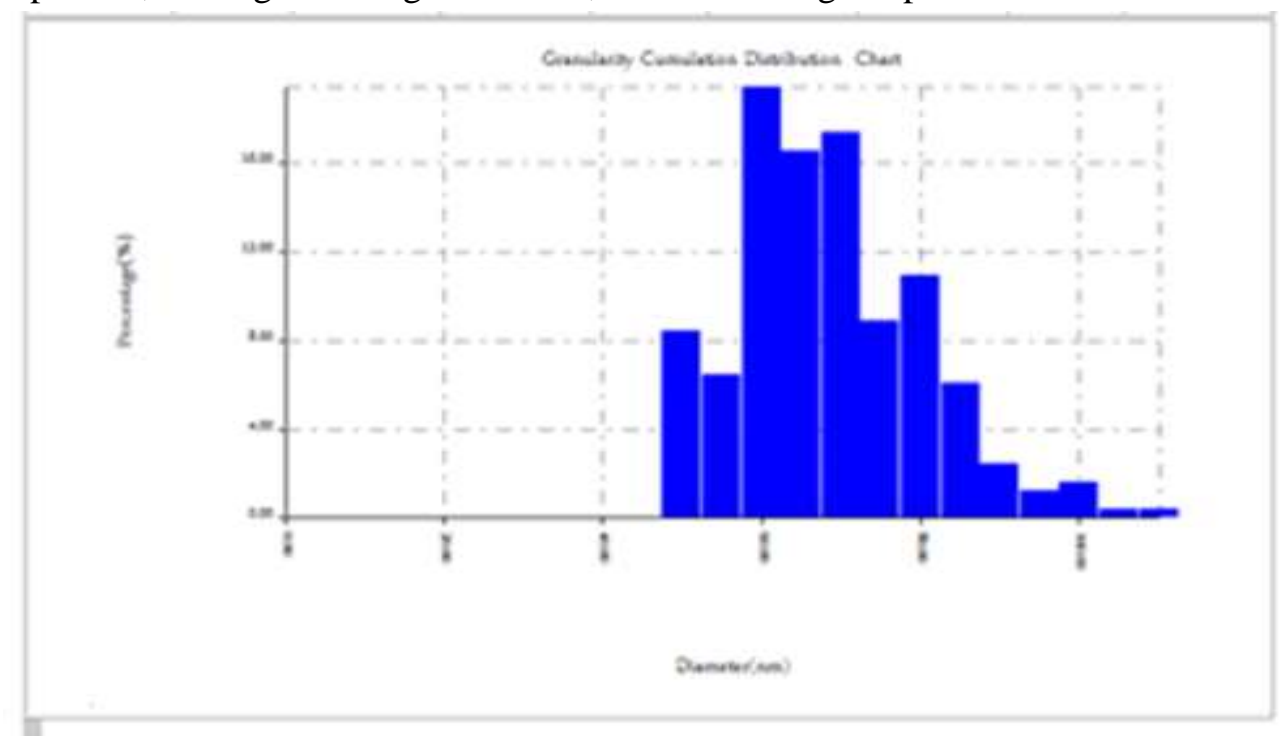

Figure 10-Granularity distribution of Ag NPs synthesized by the aqueous extract of O. vulgare and cold plasma.

\section{CONCLUSIONS}

The type of active compound that combines with the nitrate salts added with silver was determined. The study also showed how to prepare nanoparticles under the influence of cold plasma. The results showed that bulk particles became nanoparticles that could be used in various medical fields. On the other hand, it was found that under the influence of cold plasma, the size of the nanoparticles was reduced but at the same time, there was an increase in aggregation which reduced the good properties of the nanoparticles. The reddish brown color of the nanoparticles line was turned into dark brown due to the increased absorption.

\section{References}

1. Radhika P. R, Loganathan P, Logavaseekaran K, Nithiya R. and Jayabharathi V. 2016. G reen synthesis of nanoparticles their characterization \& application. World journal of pharmacy and pharmaceuyical sciences. 5(5): 254-478.

2. Khan K. and Rehman S. 2016. Wonders of Nanotechnology. Development and Prospective Applications of Nanoscience and Nanotechnology: Nanomaterials their Fascinating Attributes.1: 12-87.

3. Khan I, Saeed K. and Khan I. 2017. Nanoparticles: Properties, applications and toxicities. Arabian Journal of Chemistry.

4. Sankar R, Karthik A, Prabu A, Karthik S, Shivashangari KS and Ravikumar VJC. 2013. Origanum vulgare mediated biosynthesis of silver nanoparticles for its antibacterial and anticancer activity. 108: $80-84$

5. Hussein J, El Naggar ME, Latif YA, Medhat D, El Bana M, Refaat E and Morsy S. 2018. Solventfree and one pot synthesis of silver and zinc nanoparticles: Activity toward cell membrane component and insulin signaling pathway in experimental diabetes. Colloids and Surfaces B: Biointerfaces, 170: 76-84.

6. Tagad CK, S. R. Dugasani, R. Aiyer, S. Park, A. Kulkarni, and S. Sabharwal, 2013. Green synthesis of silver nanoparticles and their application for the development of optical fiber based hydrogen peroxide sensor. Sens. Actuators B Chem, 183: 144-149.

7. Usmani A, Dash PP. and Mishra AJMS. 2018. Metallic nanoformulations: Green synthetic approach for advanced drug delivery, Materials Science, 2(2):1-4. 
8. Mazhir, S.N., Hadi, F. W., Mazher, A.N. and Alobaidy, L.H. 2017.Texture Analysis of smear of Leukemia Blood Cells after Exposing to Cold Plasma. Baghdad Science Journal, 14(2): 403-410.

9. Isbary, G. 2009. Low-temperature argon plasma to decrease bacterial load on chronic wounds Abstracts 2nd Int. Plasma Medicine Conf. (San Antonio);49.

10. Mazhir, S. N., Abdullah, N., Rauuf, A F., Alyaa, H. A. and al-Ahmed, H. I. 2018. Effects of Gas Flow on Spectral Properties of Plasma Jet Induced by Microwave. Baghdad Science Journal. 15 (1): 81-86.

11. Mazhir, S., Ali, A. H., Abdalameer, N. K. and Hadi, F. W. 2016. Studying the effect of Cold Plasma on the Blood Using Digital Image Processing and Images Texture analysis, International conference on Signal Processing, Communication, Power and Embedded System (SCOPES) IEEE Explore Digital Library: 904-914.

12. Mazhir S N, Abdullah N A, Hazim I. al-Ahmed H. Harb N. H. and Abdalameer N.K. 2018. The Effect of Gas Flow on Plasma Parameters Induced by Microwave. Baghdad Science Journal, 15(2): 205-210.

13. Murtada JH. 2010. Study effect of aqueous origanum vulgare 1.Extract and rhodium (ш) complex on cancer cell line. Iraqi Journal of Biotechnology. 9(4): 729-740. 